\title{
A Study on the Pressure Relief Scope and the Stress Variation of Hydraulic Flushing Borehole
}

\author{
C. F.Wei ${ }^{1,2, *}$, B. $\mathrm{Li}^{1}$, H.M. $\mathrm{Li}^{3}$ and F.Z.Wang ${ }^{4}$ \\ ${ }^{1}$ State Key Laboratory Cultivation Base for Gas Geology and Gas Control, Henan Polytechnic University, Jiaozuo, 454003- China. \\ ${ }^{2}$ School of Mathematics \& Information Science, Henan Polytechnic University, Jiaozuo, 454003- China \\ ${ }^{3}$ School of Energy Science and Engineering, Henan Polytechnic University, Jiaozuo, 454003- China. \\ ${ }^{4}$ School of Electrical Engineering and Automation, Henan Polytechnic University, Jiaozuo, 454003- China
}

Received 15 June 2013; Accepted 23 January 2014

\begin{abstract}
To study the variation of the pressure relief scope and the stress around hydraulic flushing borehole, the theory of coalrock damage was utilized to distinguish the interaction area of water-jet and coal-rock into the coal-rock crushing area, the water-jet pressure stagnation area, the transition area and the original stress recovery area of coal-rock. Based on the actual occurrence conditions of the coal seam, the pressure variation and relief scope around the hydraulic flushing borehole were analyzed and simulated by RFPA ${ }^{2 \mathrm{D}}$-Flow software. The results showed that a relief area with the radius of $5.0 \sim 6.0 \mathrm{~m}$ around the borehole formed due to the hydraulic flushing with the pressure relief of $0.038 \sim 6.545 \mathrm{MPa}$, and the maximum principal stress is $15.85 \mathrm{MPa}$ with a distance of $6.8 \mathrm{~m}$ from the inspected hole where stress concentration appeared. After hydraulic flushing test, the diameter $(441.8 \sim 1171.6 \mathrm{~mm})$ of the hole which can be an expression of coal crushing area size, was calculated based on the examination of the coal amount through the trial process, and it can be drawn that the pressure relief area must be larger than that of the coal-rock crushing area. Meanwhile, the measured pressures relief range $(5.96 \sim 6.62 \mathrm{~m})$ is basically consistent with the numerical simulation result $(5.0 \sim 6.0 \mathrm{~m})$ which verified the accuracy of the simulation analysis, according to the distance from the inspection drilling to the hydraulic flushing borehole and the decreased degree of the gas content in the inspection hole by the way of Gas Content.
\end{abstract}

Keywords: Hydraulic Flushing, Pressure Relief Range, Coal-Rock, Stress, Numerical Simulation

\section{Introduction}

Based on the safety barrier of the rock roadway by using the high-pressure water-jet to impinge the coal-rock around the hydraulic flushing borehole, the coal-rock destroyed by the water-jet and eventually was discharged hole besides under the impact of the water-jet around drilling within a certain time, induced lower coal-rock stress around the borehole and higher coal permeability coefficient to improve the quantity of the drainage, and safely and quickly reduce the coal seam outburst hazard [1], [2], [3]. The coal-rock around the hydraulic flushing borehole could be crushed and discharged outside the hole by the external force (i.e. the impingement of high-pressure water jet). Then, a certain area of the pressure relief and gas emission formed according to the previous works [1], [2], where the coal permeability coefficient increased and the gas pressure decreased without the coal seam outburst hazard anymore. However, it is not clear about the change of the damage (e.g. the degree and range) of the rock mass, the variation of the pressure relief range and the stress around the hydraulic flushing borehole under the dynamic loading.

By inspecting the measuration on the effective influence radius of the hydraulic flushing [3], the objective of assigning hydraulic flushing and drills were able to be reasonably achieved through the optimization of the

\footnotetext{
* E-mail address: hpuwcf@163.com

ISSN: 1791-2377 @ 2014 Kavala Institute of Technology. All rights reserved.
}

parameters of the punching and drilling. It can be concluded that the decreased gas pressure, the amplified gas emission and the eliminated outburst hazard in pressure relief area were able to be realized by the inspection from the pressure relief and permeability improvement effect of hydraulic flushing measures [4]. The coal seam pressure relief area which has taken the hydraulic flushing measures can be divided into the full gas emission area, the gas pressure transition area and the original gas pressure area whose discharge mechanism could be analyzed using the numerical simulation [5]. The mechanism and process of breaking coal by high-pressure water-jet has also been divided into different periods at initial stage of water-jet strike dynamic loading (i.e. no transverse flow, steady flow and unloading) [6]. And three effects of the hydraulic slotting have been summed up as the crack formation, the water wedge effect and the surface erosion effect [7]. These reported works mainly aimed at the eliminated outburst effect of the hydraulic flushing, the range of pressure relief and the optimization of the drilling parameters for the hydraulic flushing measurement, however, there still lacks the studies about the broken process of the coal-rock around the hydraulic flushing borehole and its breaking range. Therefore, to study the impact of the water-jet on the breaking range and the stress distribution rule around the hydraulic flushing borehole, we simulated the nonlinearity action of coal-rock macroscopic deformation and destruction and the discontinuous and irreversible action of material based on the anisotropy of the micro-primitive physical 
science parameters with the consideration about the unit weakening described as primitive damage after the destruction of coal-rock mass. Finally, the spot survey was utilized to certificate the accuracy of theory and analyze the numerical simulation.

\section{The damage process of the coal-rock around the hydraulic flushing borehole}

The essence of the coal-rock broken by the punching waterjet is that the water-jet can impinge and cut the coal-rock in the effective distance and cause the deep damage and break of the coal-rock. When the water-jet touched the coal-rock in the effective target distance with dynamic loading, the maximum shearing stress, tensile stress and stress wave would be respectively produced below the attacked area and the contacted area surrounding the adherent point is the center radiate towards deep coal-rock [8], [9]. If no elastic interaction happened after the punching water-jet impinged and touched the coal-rock, the water-jet will flow into the inner coal-rock by steady seepage. The proceed of coal-rock yielding and breaking should happen from near to distant in turn when the water-jet impinged the coal-rock around the hydraulic flushing borehole. As shown in Fig.1, the interaction area of water-jet and coal-rock can be divided into the coal-rock broken area, the water-jet stress lag area, the transition area and the original stress recovery area of coal-rock [6].

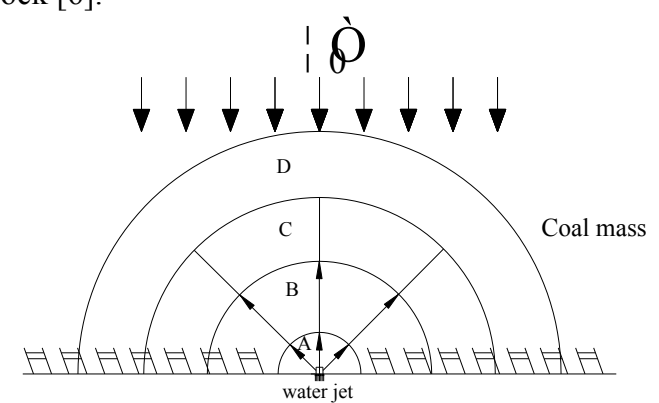

Fig. 1. The coal-rock model under the action of water-jet with the (A) coal-rock broken area, (B) water-jet pressure lag area, (C) transition area and (D) original stress recovery area of coal-rock.

A characterizes the coal-rock breaking area where the water-jet constantly produced impact loading to the coalrock and formed stress wave. Then the compressional wave spread from the liquid-solid contact edge to the liquid column centre, producing the anti-acting force at the same time. The superficial stress of the coal-rock would reach to the maximum under the effects of water-jet acting force and anti-impulsion. The fissures would generate, expand and link in the inner of the coal-rock when the superficial stress exceeded the yield stress of the coal-rock breaking in a certain order of magnitudes.

B characterizes the water-jet pressure stagnation area where the liquid column constantly extended out and the water-jet impinged the coal-rock with amplifying radius. The effective pressure of the water-jet gradually decreased in this area, and the water-jet burst into fissures and penetrated along them which were produced in the inner of the coal-rock and further extended to the surface. Finally, the coal-rock unit translated tension condition was induced by the fissures into two compression conditions, leading to the destroyed coal-rock with an incision.
$\mathrm{C}$ characterizes the transition area. When the radius of the water-jet amplified to a certain degree, its destroyed effect on the coal-rock would be less than the yield pressure which was needed for the break. Due to a large number of coal-rock around the discharged drills outside the holes under the effects of ground stress and gas pressure, the stress around drills could transfer to the deep causing the stress concentration and damage the fissures fusion with reducing permeability coefficient of coal seam.

D characterizes the original stress recovery area of coalrock where the water-jet and stress wave are unable to affect the coal-rock. The stress state will gradually recover to the initial state by constantly extending into the deep drills.

\section{The analysis of numerical simulation}

The coal-rock can be divided into several discrete elements which possess different physical and mechanical properties by the RFPA ${ }^{2 D}$-Flow software In order to solve the stress and strain state of each element, it is assumed that the mechanical property of each element obeys the distribution of Weibull regularities, and the relationship between the microcosmic and macroscopic medium mechanical property is built [10], [11].

\subsection{Constitutive relation}

$\sigma=(1-D) \widetilde{\sigma}=(1-D) E \varepsilon$

where, it is assumed that $\sigma, \widetilde{\sigma}, E,(1-D)$ and $D$ respectively represent the Cauchy stress, the effective stress, the modulus of elasticity of no damage for the coal-rock medium, the relative area of effective support inner force, and the damage parameter. The numerical model regards the meso-level break of coal-rock as the stretch and shear destroy when this imitate uses the elastic brittle constitutive model which suits to the breaking characters of the coalrock.

(1) When the unit is in the stretch state [11], the destroy variable of $\mathrm{D}$ is shown as:

$D= \begin{cases}0 & \varepsilon<\varepsilon_{t 0} \\ 1-\frac{\sigma_{t r}}{\varepsilon E_{0}} & \varepsilon_{t 0} \leq \varepsilon \leq \varepsilon_{t u} \\ 1 & \varepsilon>\varepsilon_{t u}\end{cases}$

where, it is assumed that $\sigma_{t r}, \varepsilon_{t 0}, \varepsilon_{t u}$ and $E_{0}$ respectively represent the stretch destroy residual strength, the elastic limit stretching strain, the maximum stretching strain and the initial modulus of the elasticity.

(2) When the unit is in the compression state [12], the destroy variable of $\mathrm{D}$ is shown as:

$D= \begin{cases}0 & \varepsilon<\varepsilon_{c 0} \\ 1-\frac{\sigma_{c r}}{\varepsilon E_{0}} & \varepsilon \geq \varepsilon_{c 0}\end{cases}$

where, it is assumed that $\sigma_{\text {cr }}$ and $\varepsilon_{c 0}$ respectively represent the shear destroy residual strength, and the elastic limit compressive strain.

For the uniaxial tension, the Elements' gas permeability 
coefficient-destroyed equation obeys the microcosmic element constitutive model. When the element reaches to the destroyed critical value of the tensile strength $\left(\sigma_{t}\right)$, the corresponding unit microscopic constitutive model is shown in Fig. 2 [13], [14], [15].

$$
\sigma_{3} \leq-\sigma_{t}
$$

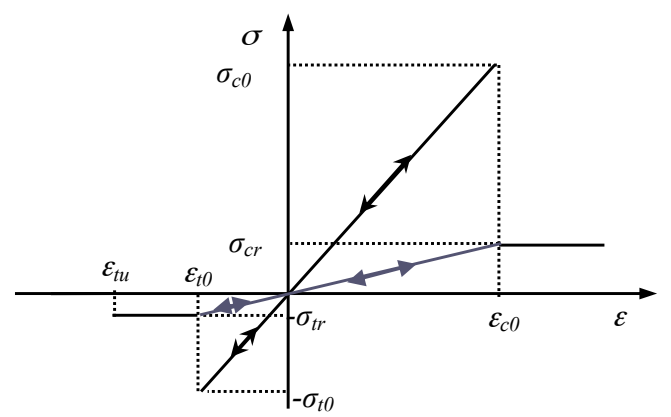

Fig. 2.The elastic constitutive law for the element under the uniaxial compressive stress and tensile stress.

\subsection{Establishment of the model}

Taking the roof and floor of coal-rock as an ideal condition, it means there are 51200 units (each unit represents an area of $0.1 \mathrm{~mm} \times 0.1 \mathrm{~mm}$ and a simulation range of $16 \mathrm{~m} \times 32 \mathrm{~m}$ ) in total for the airtight rock. The stress boundary of the numerical model is shown in Fig.3, the horizontal stress is $20 \mathrm{Mpa}$ and vertical stress is $15 \mathrm{Mpa}$. The seepage boundary of the model is shown in Fig.4, the gas pressure of the coal seam is $1.0 \mathrm{Mpa}$ and the other rock is $0 \mathrm{Mpa}$. The mechanical parameters for each stratum part rock mass are listed in Tab.1. For the simulating, the assumed radius of drills is set to be $500 \mathrm{~mm}$ according to the punching experiment (the coal output of the drills was converted into the volume of drills), to arrange the drills in the center of model and adopt the two-dimensional modeling.

In the coal-rock model, the physical science parameters of the units include the modulus of elasticity, strength, compressive strength and poisson's ratio, etc. of roof and floor, and the coal seam. These parameters are randomly allocated according to Weibull distribution. In Equation 5, e.g., where, it is assumed that s respectively represents $E_{0} 、 \sigma_{c} 、 k$; and $s_{0}$ represents the average of the three parameters mentioned above. $m$ represents the index of homogenization coefficient in the coal seam; and it is assumed that $\mathrm{m}=3$ for the roof and floor, $\mathrm{m}=2$ for the coal seam in the simulation (The special structure of the coal seam is taken into consideration).

$\varphi=\frac{m}{s_{0}}\left[\frac{s}{s_{0}}\right]^{m-1} \exp \left[-\left(\frac{s}{s_{0}}\right)^{m}\right]$

The discontinuous and irreversible actions of materials were mainly imitated based on the consideration of the unit reduction damage on the described elements after the material destruction. In this simulation test, the variation of the stress range and destroy around the hydraulic flushing borehole has been considered without the variation analysis of the coal floor stress. The coal floor was regarded as a whole with the exerted hitting power from the water-jet and the gas pressure in the coal seam drills. Additionally, the rushed out coal was assumed as the regular roundness drills to facilitate the calculation and processing.

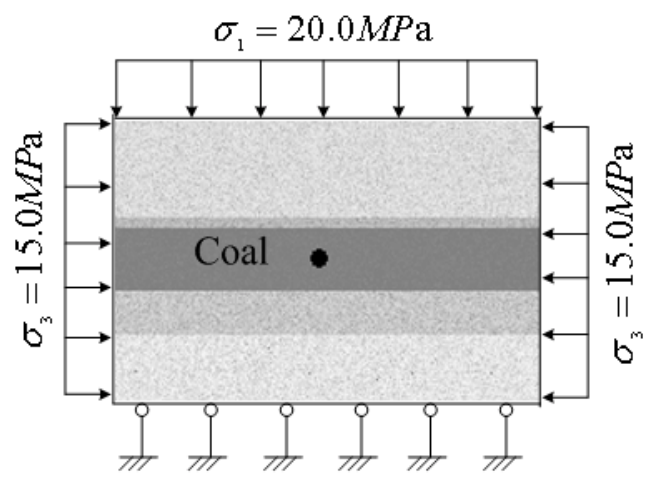

Fig. 3 Numerical mechanical model of hydraulic flushing

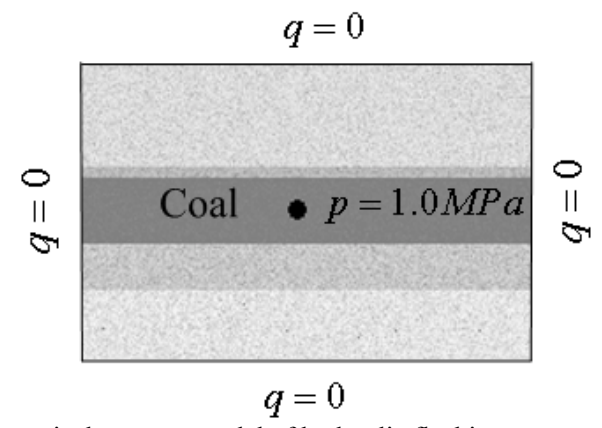

Fig. 4 Numerical seepage model of hydraulic flushing

According to the physical truth of the overlying rock, the loading condition of the model was respectively set as the upload of 7.5 and $14 \mathrm{MPa}$ towards the $\mathrm{X}$ and $\mathrm{Y}$ direction, and the hitting power of the drills water-jet was set as 1.0 $\mathrm{MPa}$ according to the nozzle style and the emulsion pump pressure used in scene. To solve the mold with plane stress, the total upload steps are fifteen and each one was shown as below.

Tab. 1. The mechanical parameters of the coal-rock.

\begin{tabular}{cccc}
\hline $\begin{array}{c}\text { Density } \\
\left(\mathrm{kg} / \mathrm{m}^{3}\right)\end{array}$ & $\begin{array}{c}\text { Thickness } \\
(\mathrm{m})\end{array}$ & $\begin{array}{c}\text { Elastic } \\
\text { modulus } \\
(\mathrm{MPa})\end{array}$ & $\begin{array}{c}\text { Poisson } \\
\text { ratio }\end{array}$ \\
\hline 1500 & 3 & 1500 & 0.3 \\
\hline $\begin{array}{c}\text { Compressive } \\
\text { strength } \\
(\mathrm{MPa})\end{array}$ & $\begin{array}{c}\text { Friction angle } \\
\left({ }^{\circ}\right)\end{array}$ & $\begin{array}{c}\text { Ratio of compressive tensile } \\
\text { strength of the rock }\end{array}$ \\
\hline 5 & 30 & \multicolumn{2}{c}{11} \\
\hline
\end{tabular}

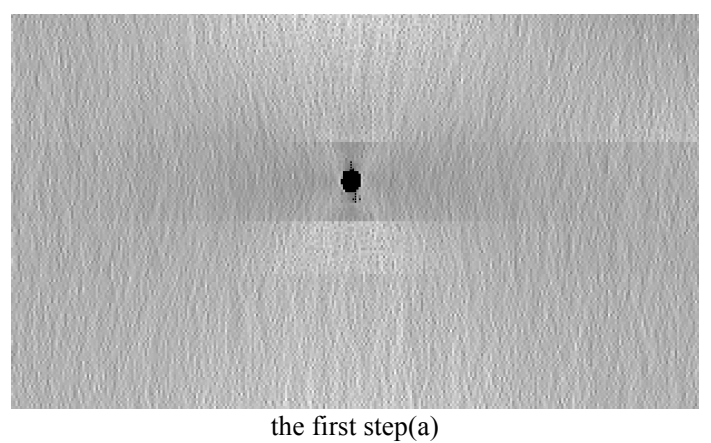




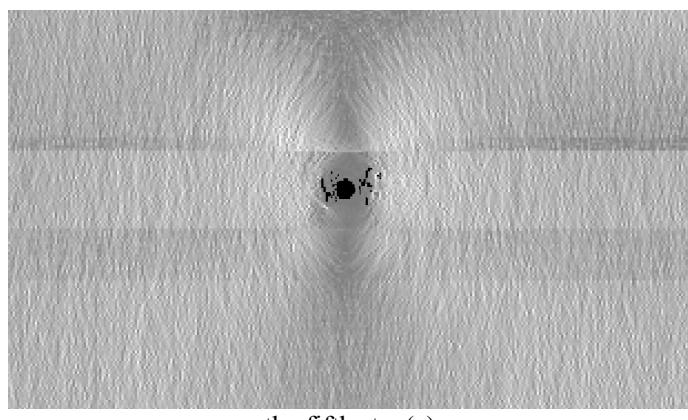

the fifth $\operatorname{step}(\mathrm{a})$

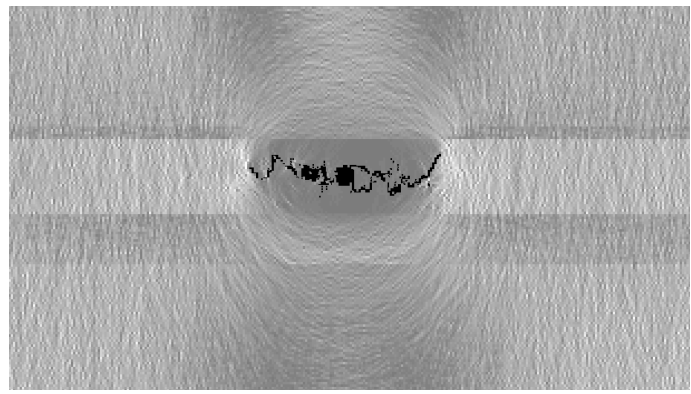

the tenth $\operatorname{step}(\mathrm{a})$

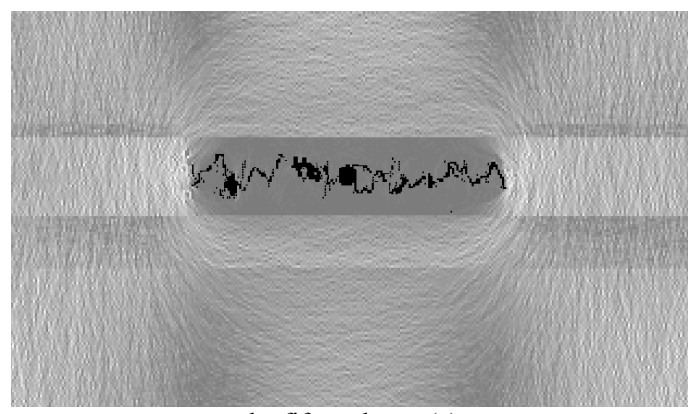

the fifteenth step(a)

Fig. 5.The cloud chart of gas pressure around the drill

\section{Analysis of the results}

Fig. 5. shows the cloud chart of gas pressure around the drill and Fig. 6 shows the distributions of the stress around the drill. The blue, red and purple colors in simulation result tinctorial respectively represent the Shear stress, Max. principal stress and Min. principal stress. The $\mathrm{X}$ and $\mathrm{Y}$ axes respectively represent the radial distances of the drills and the stress, and the core of the drills locates at $16 \mathrm{~m}$ from the $\mathrm{X}$ axis.

For the first step, it can be seen that the effect of the water-jet breaking the unstable equilibrium state of the original stress in the coal seam caused the expansion of the fissures around the coal seam, the propagation of the fissures depth, the development of the pressure relief scope, the transformation of the stress in the pressure relief scope, the amplification of the coal seam permeability, the dilatancy of the coal and the reduction of the gas pressure. According to the analysis as described above, the pressure relief scope includes the coal-rock crushing area and the water-jet pressure stagnation area. Fig. 6 shows the radius of the pressure relief is about $1.5 \sim 2.0 \mathrm{~m}$ and the stress is within $0.252 \sim 3.706 \mathrm{MPa}$. There is a region calling the transition zone where the stress with a radius of $2 \sim 3.2 \mathrm{~m}$ gradually increased and partly appeared to be the stress concentration. At a distance of $3.2 \mathrm{~m}$ from the inspected drill, the maximum
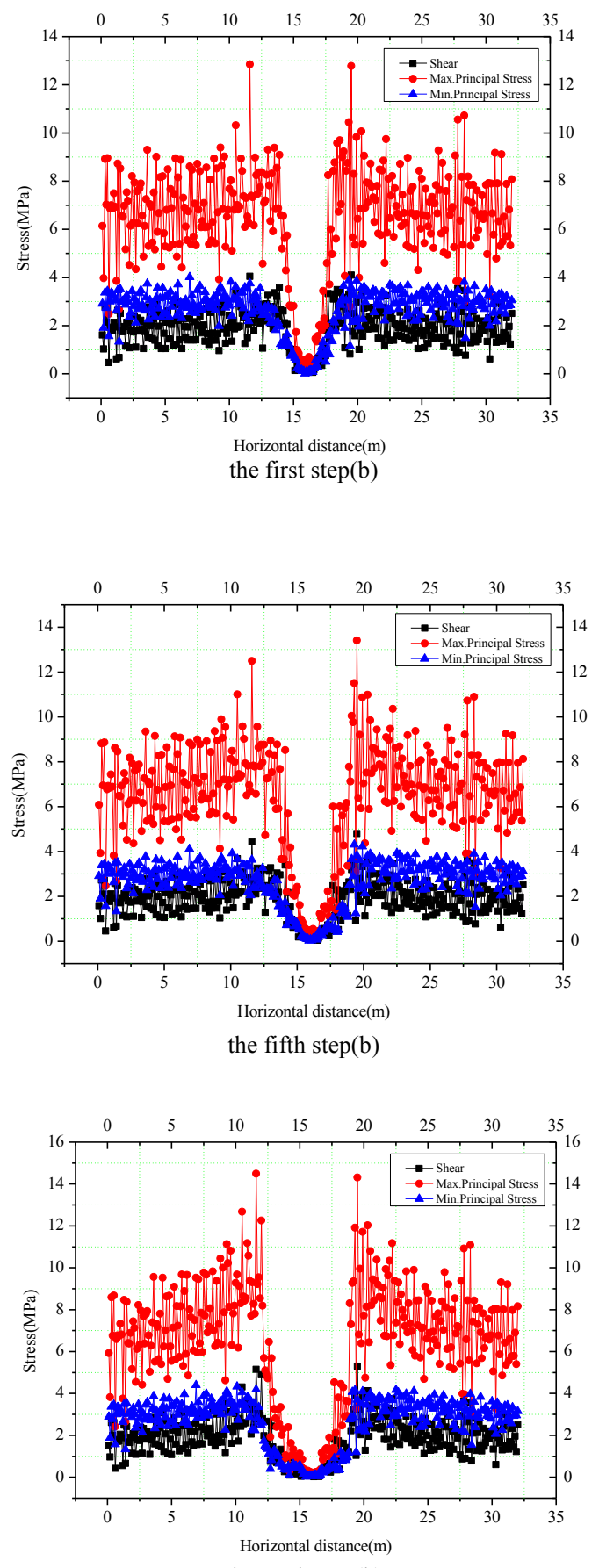

the tenth step(b)

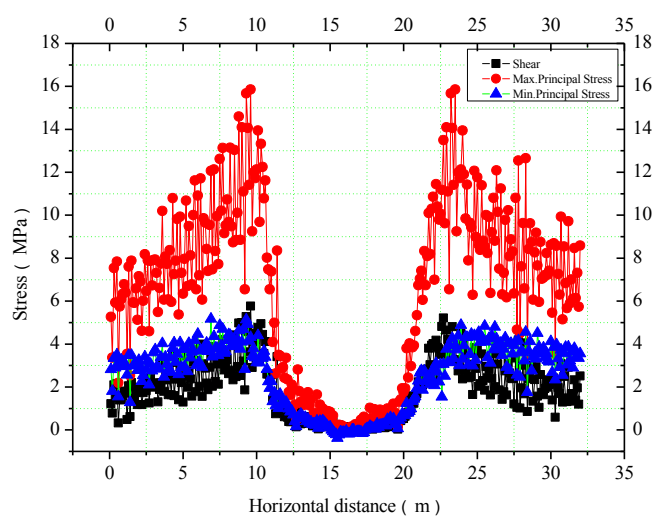

the fifteenth $\operatorname{step}(b)$

Fig.6.The dynamic distribution of the stress around the drill 
principal stress can reach $13.84 \mathrm{MPa}$ under the influence of the ground stress and the gas pressure. In the original stress area, the regional coal seam beyond the pressure relief scope will reconfigure the stability.

From the fifth to the tenth step with the punching time extension, it can be observed that a large number of the coal mass were discharged outside the holes, the destruction scope gradually increased, the coal seam fissures extending towards to the deep and a large-scale pressure relief scope formed. At the fifth step, the coal-rock crushing area and the water-jet pressure stagnation area reached to a radius of $2.5 \sim 3.0 \mathrm{~m}$, a stress of $0.490 \sim 3.650 \mathrm{MPa}$ and a transition area of $3.0 \sim 4.4 \mathrm{~m}$. As the stress gradually increased, the Max. principal stress could reach $12.48 \mathrm{MPa}$ which was $4.4 \mathrm{~m}$ away from the inspected hole.

Afterwards, from the tenth to the fifteenth step, the coalrock crushing area and the water-jet pressure lag area reached to a radius of $3.0 \sim 4.0 \mathrm{~m}$ and a stress of $0.092 \sim 4.100$ $\mathrm{MPa}$. As the stress gradually increased between $4.0 \sim 5.4 \mathrm{~m}$, the Max. principal stress could reach $14.48 \mathrm{MPa}$ at a distance of $5.4 \mathrm{~m}$ away from the inspected hole.

For the fifteenth step, the coal-rock crushing area and water-jet pressure lag area could reach to a radius of 5.0 6.0 $\mathrm{m}$ and a stress of $0.038 \sim 6.545 \mathrm{MPa}$. If the coal mass was affected by the hydraulic flushing borehole in the pressure relief area, the fissures would develop and expand causing the sudden drop of the stress and the gas pressure in this area. With less distance to the drills, the drop of the stress and gas pressure became more serious. The Max. principal stress was $15.85 \mathrm{MPa}$ at a distance of $6.8 \mathrm{~m}$ away from the inspected hole.

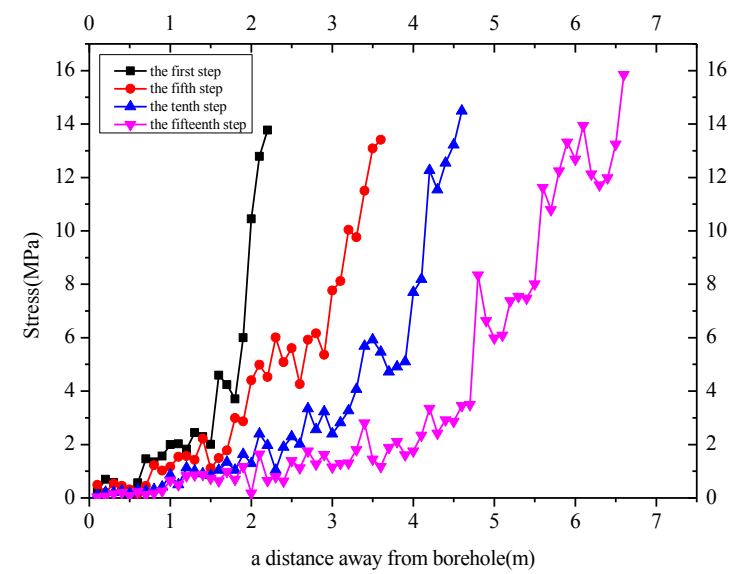

Fig. 6. The change of the max. principal stress in the pressure relief range.

In Fig. 6, it can be observed that the stress increased with the distance away from the drills. When the hydraulic flushing borehole is finished, the pressure relief is $5.0 \sim 6.0 \mathrm{~m}$. The numerical modeling could visually reflect the variation of the stress relief scope around the hydraulic flushing borehole, and reveal the formation process and the range of the coal-rock crushing area, the water-jet pressure lag area, the transition area and the original stress recovery area of coal-rock mass.

\section{Field validity}

In order to check the range and the change of the gas pressure in the coal-rock crushing area and the water-jet pressure lag area, the coal output and the remained gas content were respectively determined. The range of the coal- rock crushing area was characterized based on the amount of coal output and its corresponding drills volume, while the range and extent of pressure relief were characterized based on the distance from the inspection drills to the punching drill and the descent extent of the gas content.

\subsection{Measurement of the coal output}

In this work, the aperture of the hydraulic flushing test is 89 $\mathrm{mm}$. Through constantly crushing the coal by the water-jet impinge, a lot of coal discharged outside the drills and holes formed around the drills. The coal output is more than $5 \mathrm{t}$ for a signal hole (1t per meter). Based on the length and the coal output for each drills and coal holes, the true density of the coal is $1.45 \mathrm{~kg} / \mathrm{m}^{3}$ and the volume of the drills is $2.35 \sim 3.44$ $\mathrm{m}^{3}$. The diameter of the holes around the drills is calculated to be $441.8 \sim 1171.62 \mathrm{~mm}$ and the expansion mulriple of the aperture is $4.96 \sim 13.16$. When the hydraulic flushing test finished, the radius of the coal-rock crushing area and the water-jet pressure lag area reached $5.0 \sim 6.0 \mathrm{~m}$. It can be deduced that the range of the coal-rock crushing area is less than that of the water-jet pressure lag area according to these simulated results.

Although the holes formed by the water-jet impinging crushing coal did not exist in the process of mining and tunneling, the coal seam bedding have obviously changed to move towards the holes. And a certain range pressure relief area after the water-jet impinged crushing coal formed. As described above, the pressure relief area is much larger than the coal-rock crushing area. The stress concentration transferred towards the deep coal after punching affected by the stress and the gas pressure. After a period of displacement, the coal displacement increased around the holes, and the changes of coal seam bedding appeared around the drills due to the holes filled with coal from surrounding.

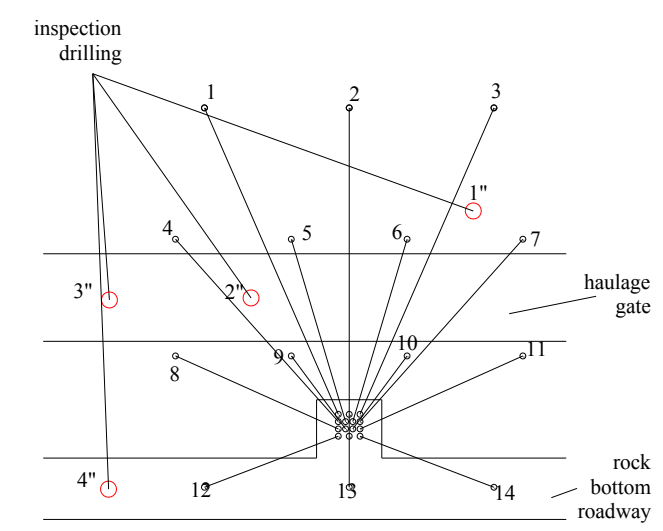

Fig. 7.The inspection of the drilling layout parameters.

\subsection{Determination of the residual amount}

Before the field test of the hydraulic flushing borehole, the original gas content and gas pressure were respectively determined for the four groups of the coal seam in the test area. The range of the gas content and its average value is respectively $8.93 \sim 9.87 \mathrm{~m}^{3} / \mathrm{t}$ and $9.4 \mathrm{~m}^{3} / \mathrm{t}$, while those of the gas pressure is $0.8 \sim 0.95 \mathrm{MPa}$ and $0.88 \mathrm{MPa}$, according to the data analysis of the coal seam in the area possess possibility of the coal and gas outbursts. An appropriate location in the test site has been chosen to verify the range of the pressure relief area and the descent extent of the gas pressure, and the gas content and the gas pressure in the pressure relief area and margins were re-determined. The 
results indicate the minimum coal seam gas content is 3.60 $\mathrm{m}^{3} / \mathrm{t}$. Although the gas pressure was not directly measured due to the fissures interconnected in the pressure relief area, the inverted gas pressure is estimated to be $0.21 \mathrm{MPa}$ in the pressure relief area utilizing the Langmuir equation. The layout chart of the drills and the inspection drilling are shown in Fig.7.

In Tab.2, the data indicate that the decline of the gas content became greater with the closer distance of the inspection drilling away from the punching drilling. Within the punch radius of $5.96 \mathrm{~m}$, the gas content was below the critical value. And the area achieved the outburst elimination effect if the drill pressure relief range is more than $5.96 \mathrm{~m}$. The content of the gas is $7.86 \mathrm{~m}^{3} / \mathrm{t}$ at the position where is $6.62 \mathrm{~m}$ away from the punching drilling. Although the gas content has dropped $16.3 \%$ to the critical value, the effect from the hydraulic flushing borehole and the water-jet is not obvious, indicating it should belong to the transition area. Thus, it can be concluded that the pressure relief ranges from 5.96 to $6.62 \mathrm{~m}$, which is basically consistent with the numerical simulation result $(5.0 \sim 6.0 \mathrm{~m})$ and verifies the accuracy of the simulation results.

Tab.2. The parameters of the inspection drilling.

\begin{tabular}{cccc}
\hline $\begin{array}{c}\text { Sampling } \\
\text { location }\end{array}$ & $\begin{array}{c}\text { Closest } \\
\text { distance from } \\
\text { test drilling }\end{array}$ & $\begin{array}{c}\text { Residual } \\
\text { gas content } \\
\left(\mathrm{m}^{3} / \mathrm{t}\right)\end{array}$ & $\begin{array}{c}\text { Decline } \\
\%\end{array}$ \\
\hline 1" & 3.93 & 3.60 & $61.7 \%$ \\
2" & 4.89 & 4.92 & $47.6 \%$ \\
3" & 5.96 & 5.15 & $45.2 \%$ \\
4" & 6.62 & 7.86 & $16.3 \%$ \\
\hline
\end{tabular}

\section{Conclusions}

Utilizing the theory of water-jet strike destroy, the destroy effect of the coal-rock around the hydraulic flushing borehole by water-jet has been analyzed. The interaction area of the water-jet and the coal-rock can be divided into the coal-rock crushing area, the water-jet pressure lag area, the transition area and the original stress recovery area of coal-rock. Combined with the numerical simulation results, it indicates the punching water-jet destroyed the coal and broke the intrinsic stable equilibrium of the ground stress and the gas pressure. A large number of coals around the boreholes discharged outside the drills under the effect of the stress and the gas pressure. The stress redistributed around the borehole and the stress concentration has extended towards to the deep. When the measures of the hydraulic flushing finished, an area of the pressure relief scope formed with a radius of $5.0 \sim 6.0 \mathrm{~m}$ and the stress range from 0.038 to 6.545 MPa. The Max. principal stress could reach 15.85 $\mathrm{MPa}$ at a distance of $6.8 \mathrm{~m}$ away from the inspected hole.

In order to investigate the range of the fracture area, the range of coal-rock crushing area was characterized according to the amount of the coal output which was used to convert into the corresponding drills volume. Based on the data of the coal output $(>5 \mathrm{t}$ for a signal hole $(1 \mathrm{t}$ per meter)), the volume of the drills is worked out as 2.35 3.44 $\mathrm{m}^{3}$ and the diameter of the hole which is around the drills is 441.8 1171.62 $\mathrm{mm}$. The content of the gas and the gas pressure in pressure relief area and margins were redetermined to verify the range of the pressure relief area and the descent extent of the gas pressure. The results of the comparative analysis show the decline of the gas content became greater with the closer distance of the inspection drilling away from the punching drilling. According to the distance from the inspection drilling to the punching drilling and the decrease extent of the gas content, it can be concluded that the pressure relief range is $5.96 \sim 6.62 \mathrm{~m}$, which is basically consistent with the result of numerical simulation $(5.0 \sim 6.0 \mathrm{~m})$ and verifies the accuracy of the simulation results.

\section{Acknowledgements}

The work is partially supported by the National Natural Science Foundation of China (51274086), The national 973 Project of China (2012CB723103), the Ministry of education Doctoral Foundation of China-priority areas (201241161 30001), the State Key Laboratory Cultivation Base for Gas Geology and Gas Control (Henan Polytechnic University) of China (WS2012A10), Doctoral Fund of Henan Polytechnic University of China (B2011-064).

\section{References}

1. Yang, Y.-F., Wang, N.-H., "Analysis on pressure releasing and permeability improving technology with hydraulic borehole jetting in Yi'an mine", Coal Science and Technology 38 (7), 2010, pp. 4851.

2. Liu, M.-J., Kong, L.-A., Hao, F.-C., "Application of hydraulic flushing technology in severe outburst coal", Journal of China Coal Society 30 (4), 2005, pp. 451-454.

3. Wei, J.-P., Li, B., Liu, M.-J., "Measuration on effective influence radius of hydraulic flushing borehole to eliminate outburst and borehole parameters optimization", Coal Science and Technology 38 (5), 2010, pp. 39-42.

4. Liu, Y.-W., Ren, P.-L., Xia, S.-B., "Analysis of pressure-relief and permeability improvement effect of hydraulic flushing", Journal of Henan Polytechnic University (Natural Science) 28 (6), 2009, pp. 695-699.

5. Wang, X.-X., Shi, B.-M., Mu, C.-M., "Study on formation mechanism of gas emission partition in hydraulic flushing coal seam”, Journal of China Coal Society 37 (3), 2012, pp. 467-471.

6. Liang, Y.P., "Study On The Mechanism of Coal Failure By Drilling of High Pressure Water Jetting”, Shandong: ShanDong University of Science and Technology, 2007.

7. Wei, G.-Y., "Mechanism and Technique of Hydraulic Slotting for Coal-gas Outbursts Control", Jiaozuo: Henan Polytechnic University, 2008.
8. Li, G.-S., Liao, H.-L., Huang, Z.-W., "Rock Damage Mechanisms under Ultra-high. Pressure Water Jet Impact", Journal of Mechanical Engineering 45 (10), 2009, pp. 284-293.

9. Ni, H.-J., Wang, R.-H., Zhang, Y.-Q., "Numerical simulation study on rock breaking mechanism and process under high pressure water jet", Applied Mathematics and Mechanics 26(12), 2005, pp.14451452 .

10. Tang, C.-A., "Catastrophe in rock unstable failure", Beijing: Coal industry press, 1993.

11. Ni, H.-J., Wang, R.-H., Ge, H.-K., "Numerical simulation on rock breaking under high pressure water jet", Chinese Journal of Rock Mechanics and Engineering 23(4), 2004, pp.550-554.

12. Tang C.-A. "Experiment of Mining Rock Burst and Stratum Move Value", Changchun: Jilin University Press, 2003.

13. Cao W.-G., Zhao, M.-H., Tang, X.-J., "Study on Simulation of Statistical Damage in The Full Process of Rock failure", Chinese Jounal of Geotechnical Engineering 25(2), 2003, pp.184-187.

14. Yang, T.-H., Yu Q.-L., Wang, S.Y., et al. "Study on Crack Coal escence Process under Loading and Hydraulic Pressures", Chinese Journal of Rock Mechanics and Engineering 24 (1) 2005, pp.50265030.

15. Yang T.-H., Tang C.-A., Xu T., "Model and Application of Seepage Characteristic Theory in Rock Failure Process", Beijing: Science Press, 2004. 